\begin{tabular}{|c|c|}
\hline Title & $\begin{array}{l}\text { The Effects of Nitrogen and Plasma Power on Electrochemical Properties of Boron-Doped Diamond Electrodes Grown } \\
\text { by MPCVD }\end{array}$ \\
\hline Author(s) & Y agi, Ichizo; Tsunozaki, Kentaro; Fuji ishima, A kira; Ohtani, Bunsho; U osaki, Kohei \\
\hline Citation & $\begin{array}{l}\text { Journal of The Electrochemical Society, 149(1), E1-E5 } \\
\text { https://doi.org/10.1149/1.1425795 }\end{array}$ \\
\hline Issue Date & 2002 \\
\hline Doc URL & http:/hdl.handle.net $/ 2115 / 50233$ \\
\hline Rights & $\begin{array}{l}\text { () The Electrochemical Society, Inc. 2001. All rights reserved. Except as provided under U.S. copyright law, this work } \\
\text { may not be reproduced, resold, distributed, or modified without the express permission of The Electrochemical Society } \\
\text { (ECS). The archival version of this work was published in J. Electrochem. Soc. } 2002 \text { volume 149, issue 1, E1-E5. }\end{array}$ \\
\hline Type & article \\
\hline File Information & JES149-1_E1-E5.pdf \\
\hline
\end{tabular}

Instructions for use 


\section{The Effects of Nitrogen and Plasma Power on Electrochemical Properties of Boron-Doped Diamond Electrodes Grown by MPCVD}

Ichizo Yagi, Kentaro Tsunozaki, Akira Fujishima, Bunsho Ohtani and Kohei Uosaki

J. Electrochem. Soc. 2002, Volume 149, Issue 1, Pages E1-E5. doi: $10.1149 / 1.1425795$

\section{Email alerting Receive free email alerts when new articles cite this article - sign up in the service box at the top right corner of the article or click here}




\title{
The Effects of Nitrogen and Plasma Power on Electrochemical Properties of Boron-Doped Diamond Electrodes Grown by MPCVD
}

\author{
Ichizo Yagi, ${ }^{\mathrm{a}, \mathrm{z}}$ Kentaro Tsunozaki, ${ }^{\mathrm{b}}$ Akira Fujishima, ${ }^{\mathrm{b}, *}$ Bunsho Ohtani, ${ }^{\mathrm{c}}$ \\ and Kohei Uosaki ${ }^{\mathrm{a}, *}$ \\ ${ }^{a}$ Physical Chemistry Laboratory, Division of Chemistry, Graduate School of Science, Hokkaido University, \\ Sapporo 060-0810, Japan \\ ${ }^{b}$ Department of Applied Chemistry, School of Engineering, The University of Tokyo, \\ Tokyo 113-8656, Japan \\ ${ }^{c}$ Catalysis Research Center, Hokkaido University, Sapporo 060-0811, Japan
}

\begin{abstract}
The influences of nitrogen addition and the attenuation of microwave power during microwave plasma-assisted chemical vapor deposition (MPCVD) of diamond films on electrochemical properties of the grown films were investigated. Although diamond films grown in the presence of a small amount of nitrogen did not contain $\mathrm{sp}^{2}$ carbon and appeared to be normally deposited films, the electrical and electrochemical properties were different from films grown under an atmosphere without nitrogen. Especially, the potential windows of diamond films grown in the presence of nitrogen at low microwave power were very wide and extended to $3.6 \mathrm{~V}$ in sulfuric acid solution, which is comparable to the widest value of the potential window of diamond electrodes reported till now. It was also found that the attenuation of the plasma power during MPCVD by itself was effective in the expansion of the potential window because of the defect-free growth of diamond crystals.
\end{abstract}

(C) 2001 The Electrochemical Society. [DOI: 10.1149/1.1425795] All rights reserved.

Manuscript submitted March 26, 2001; revised manuscript received August 15, 2001. Available electronically December 3, 2001.

Boron-doped diamond (BDD) thin films have become an attractive electrode material because of their unique electrochemical properties such as a small background current, wide potential window, chemical stability, and good response to certain redox species. ${ }^{1-4}$ These features seem to result from the fully covalent bonding of $\mathrm{sp}^{3}$-type carbon and the stable chemical termination of the diamond surface by hydrogen or oxygen atoms.

Because BDD is a p-type semiconductor, trials to obtain an n-type semiconducting diamond have been carried out by doping $\mathrm{N}$ or $\mathrm{P}$ atoms into the diamond lattice. Although such attempts ${ }^{5}$ have not been completely successful, an interesting effect caused by impurity addition during microwave plasma-assisted chemical vapor deposition (MPCVD) and flame deposition processes on the surface properties of diamond thin films has been reported.

Furthermore, carbon materials containing nitrogen atoms emerged as a new electrode material. For example, Yoo et al. reported that nitrogen-incorporated tetrahedral amorphous carbon showed a larger potential window than that of a diamond electrode. ${ }^{6}$ A graphite-like $\mathrm{B} / \mathrm{C} / \mathrm{N}$ compound has also been developed by several research groups. ${ }^{7-10}$ This material shows a moderate characteristics lying between graphite and boron nitride (c-BN). For example, $\mathrm{B} / \mathrm{C} / \mathrm{N}$ compounds are relatively large bandgap semiconductors, and the electrical character ( $n$ - or p-type) can be controlled easily by changing the composition ratio of $\mathrm{B}$ and $\mathrm{N}$. Thus, various applications such as electrode materials for secondary batteries, lightemitting materials, and high temperature devices can be achieved by making $\mathrm{B} / \mathrm{C} / \mathrm{N}$ films and controlling their composition.

As far as diamond film growth is concerned, nitrogen dosing has been investigated, and it has been found that the crystal structure of diamond is strongly dependent on the flow rate and partial pressure of nitrogen gas in the reaction chamber during CVD. ${ }^{11-14}$ First, Locher et al. reported the promotion of (100) textured growth of diamond particles by addition of nitrogen in the source gas $\left(\mathrm{CH}_{4}+\mathrm{H}_{2}\right) \cdot{ }^{13}$ Since then, Asmussen et al. ${ }^{12}$ and Schermer et al. ${ }^{14}$ showed that the (100) faceted films were obtained by the addition of a small amount of nitrogen during the growth of diamond film.

In addition to the atmosphere in the CVD chamber, various parameters affect both the structure and properties of the film. BDD electrodes reported up to now have been grown using different CVD

\footnotetext{
* Electrochemical Society Active Member

${ }^{\mathrm{z}}$ E-mail: yagi@pchem.sci.hokudai.ac.jp
}

methods, plasma power, growth temperature, boron concentration, and so on. These differences caused small but serious changes in both the morphology and the electrochemical properties of the diamond films. A systematic investigation should be done to understand the importance of the parameters.

In the present study, the effects of nitrogen addition and the variation of plasma power during MPCVD on the electrochemical properties of BDD electrodes were separately investigated. These two parameters were effective in the broadening of the potential window, which is important for expanding the applicability of BDD electrodes as electrochemical sensor materials, mainly for the high performance liquid chromatography electrochemical detection systems.

\section{Experimental}

B-doped polycrystalline diamond thin films were grown using a $1.5 \mathrm{~kW}$ MPCVD system (ASTeX Corp., AX5000) on highly conductive $\mathrm{n}-\mathrm{Si}(111)(\leqslant 0.01 \Omega \mathrm{cm})$. In this system, a sample stage was heated to $773-1173 \mathrm{~K}$. In this temperature region, it is known that a good quality diamond can be grown even under small plasma power. To examine the influence of plasma power, a $5 \mathrm{~kW}$ MPCVD system (ASTeX Corp., AX4200) was also used. Since the diameter of the plasma generation electrode was $2.0 \mathrm{in}$. in both systems, the difference in the plasma power density between two systems can be indicated by plasma power. Hydrogen plasma was generated in the growth chamber under the hydrogen flow. An acetone/methanol mixed solution containing $\mathrm{B}_{2} \mathrm{O}_{3}\left(\mathrm{~B} / \mathrm{C}\right.$ mole ratio was $1-2 \times 10^{3}$ ppm) was used as the carbon and boron sources, and nitrogen was bubbled into this solution to introduce carbon, boron, and nitrogen into the growth chamber. The flow rate of nitrogen was $\leqslant 5$ standard cubic centimeters per minute, which was $\leqslant 2 \%$ of the hydrogen flow. Normally, we use hydrogen to introduce carbon and boron sources into the chamber to avoid the influence of other gases. For example, hereafter, we use Dia $\left[10^{4} \mathrm{ppm}, 1.5 \mathrm{~kW}\right]$ to denote diamond films that were grown from a solution of $\mathrm{B} / \mathrm{C}=10^{4} \mathrm{ppm}$ bubbled with hydrogen at $1.5 \mathrm{~kW}$ plasma power and use N-Dia $\left[2 \times 10^{4} \mathrm{ppm}, 5\right.$ $\mathrm{kW}$ ] to denote diamond films grown from the solution of $\mathrm{B} / \mathrm{C}=2$ $\times 10^{4} \mathrm{ppm}$ bubbled with nitrogen at $5 \mathrm{~kW}$ plasma power. If the growth conditions, such as $\mathrm{B} / \mathrm{C}$ ratio of source solution, plasma power, changed, the notation for diamond films matches.

X-ray photoelectron spectroscopy (XPS) was carried out with a Rika-Denki XPS spectrometer using a Mg K $\alpha$ X-ray source. Depth 
profile of XPS was obtained by repeating Ar sputtering and measurement cycles. Electrochemical measurements were carried out using a three-electrode configuration with a Pt counter electrode and an $\mathrm{Ag} / \mathrm{AgCl}$ (saturated $\mathrm{NaCl}$ ) as a reference. Cyclic voltammograms (CVs) were recorded in $0.1 \mathrm{M} \mathrm{H}_{2} \mathrm{SO}_{4}$ or $0.1 \mathrm{M} \mathrm{Na}_{2} \mathrm{SO}_{4}$ solution. The redox behavior of $\mathrm{Fe}(\mathrm{CN})_{6}^{4-13-}$ was also studied at the diamond electrodes.

\section{Results and Discussion}

Effect of plasma power.-Attenuation of the plasma power caused a reduction of the deposition rate resulting in diamond films with one tenth the thickness and a smaller crystal size. For example, diamond films of $2.5 \mu \mathrm{m}$ thickness were grown with a $1.5 \mathrm{~kW}$ MPCVD system for $10 \mathrm{~h}$, although diamond films of about $30 \mu \mathrm{m}$ thickness can be obtained by a $5 \mathrm{~kW}$ system in the same growth time. However, the quite good quality of the diamond crystals grown in the low plasma power regime was confirmed by Raman spectra, which showed only the peaks assigned to the $\mathrm{sp}^{3}$ carbons (diamond and amorphous). Details of the Raman spectra are discussed later.

Figure 1 shows the CVs of (a) Dia $\left[10^{4} \mathrm{ppm}, 5 \mathrm{~kW}\right]$ and (b) Dia $\left[10^{4} \mathrm{ppm}, 1.5 \mathrm{~kW}\right]$ in $0.1 \mathrm{M} \mathrm{H}_{2} \mathrm{SO}_{4}$ solution. Other growth conditions were the same except for the plasma power. In the low plasma power regime, the potential window was expanded to $3.5 \mathrm{~V}$, which is the widest value reported for polycrystalline diamond electrodes. ${ }^{15}$ It is apparent that attenuation of plasma power caused an increase in overpotentials of both hydrogen and oxygen evolution. Attenuation of the plasma power caused both slower crystal growth and decrease in etching rate for the diamond film surface by the hydrogen plasma itself, resulting in a defect-free crystal growth. Both experimental $^{16}$ and theoretical ${ }^{17}$ investigations on the electron field emission from diamond thin films have also indicated that the defect-induced midgap states played important roles. Hydrogen and oxygen evolutions are inner-Helmholtz multielectron transfer reactions, therefore, they cannot be easily compared with field emission, but the defect states may serve as an electron pathway. Although the active sites for hydrogen and oxygen evolutions at a polycrystalline diamond surface have not yet been identified, the reduction of the defects in the diamond crystals is expected to cause larger overpotentials for the hydrogen and oxygen evolutions.

Effect of the presence of nitrogen during MPCVD.-Addition of nitrogen during MPCVD growth did not affect the apparent structure of the diamond films. However, the Raman spectrum of the N-Dia $\left[10^{4} \mathrm{ppm}, 1.5 \mathrm{~kW}\right]$ (Fig. 2a) was different from those of Dia $\left[10^{4}\right.$

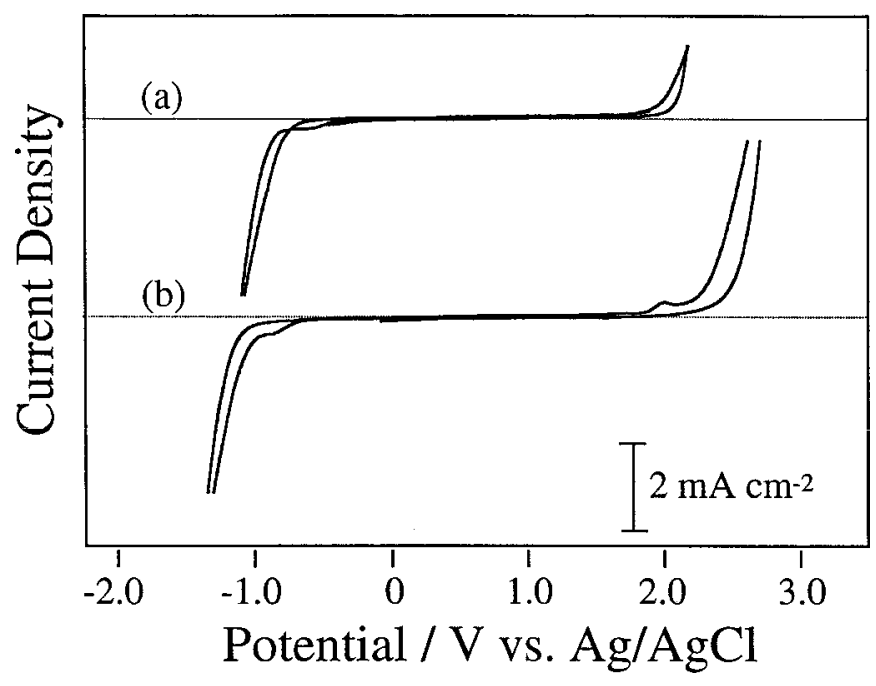

Figure 1. CVs of (a) Dia [ $\left.10^{4} \mathrm{ppm}, 5 \mathrm{~kW}\right]$ and (b) Dia [ $\left.10^{4} \mathrm{ppm}, 1.5 \mathrm{~kW}\right]$ electrodes in $0.1 \mathrm{M} \mathrm{H}_{2} \mathrm{SO}_{4}$ solution. Sweep rate was $100 \mathrm{mV} \mathrm{s}^{-1}$.

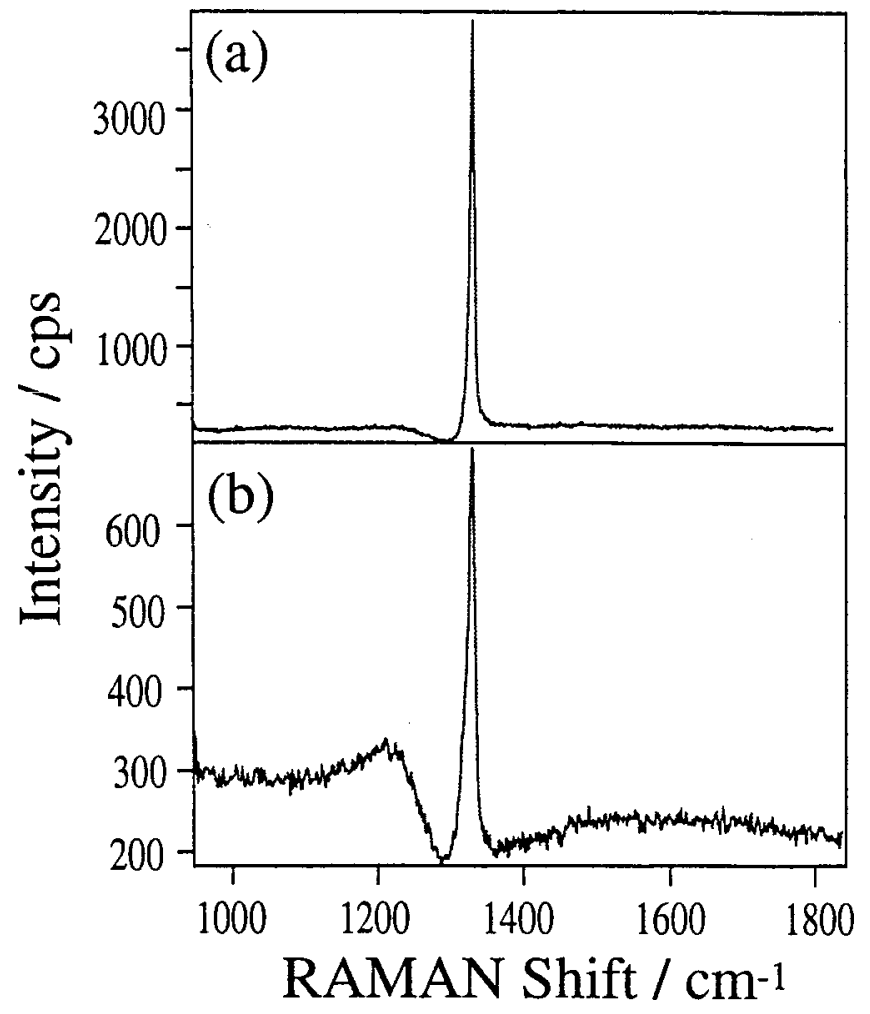

Figure 2. Raman spectra of (a) the N-Dia $\left[10^{4} \mathrm{ppm}, 1.5 \mathrm{~kW}\right]$ and (b) Dia $\left[10^{4} \mathrm{ppm}, 5 \mathrm{~kW}\right]$ films.

ppm, $1.5 \mathrm{~kW}$ (Fig. 2b). In Fig. 2a, no peak around $1200 \mathrm{~cm}^{-1}$ corresponding to the amorphous $\mathrm{sp}^{3}$ is apparent, although a broad peak is significant in Fig. 2b. It has been well known that a larger boron concentration in diamond crystal causes a larger amorphous $\mathrm{sp}^{3}$ peak around $1200 \mathrm{~cm}^{-1} \cdot{ }^{18-20}$ The absence of the peak at 1200 $\mathrm{cm}^{-1}$ in Fig. 2a indicated a smaller amount of boron in the diamond crystals of N-Dia $\left[10^{4} \mathrm{ppm}, 1.5 \mathrm{~kW}\right]$ than the value expected from the $\mathrm{B} / \mathrm{C}$ source solution. Therefore, we speculated that the small amount of nitrogen existing in the MPCVD chamber may have prevented the boron from being incorporated into the diamond lattice. Sonoda et al. reported ${ }^{21}$ the improvement in electrical conductivity of BDD film by reducing the slight amount of nitrogen in as received methane source gases during MPCVD. They also indicated the reduction of hole concentration by the presence of nitrogen, and this supports our speculation. Therefore, to increase the boron concentration in a grown diamond film, an increase in the boron concentration in the source gas or solution should be required in the presence of nitrogen. The Raman spectrum of N-Dia $\left[2 \times 10^{4} \mathrm{ppm}, 1.5 \mathrm{~kW}\right]$ showed a broad peak at $1200 \mathrm{~cm}^{-1}$ corresponding to the amorphous $\mathrm{sp}^{3}$ and resembled Fig. $2 \mathrm{~b}$.

Figure 3 shows the CVs of diamond electrodes, which were grown from the solution of (a) N-Dia $\left[10^{4} \mathrm{ppm}, 1.5 \mathrm{~kW}\right]$ and (b) $\mathrm{N}$-Dia $\left[2 \times 10^{4} \mathrm{ppm}, 1.5 \mathrm{~kW}\right.$ ], measured in $0.1 \mathrm{M} \mathrm{Na}_{2} \mathrm{SO}_{4}$ solution containing $\mathrm{K}_{3} \mathrm{Fe}(\mathrm{CN})_{6}$. The peak separation between the anodic and cathodic peaks of N-Dia [ $\left.10^{4} \mathrm{ppm}, 1.5 \mathrm{~kW}\right]$ was $c a .265 \mathrm{mV}$, which is twice that observed for Dia $\left[10^{4} \mathrm{ppm}, 1.5 \mathrm{~kW}\right]$. When the $\mathrm{B} / \mathrm{C}$ ratio in the source solution was increased to $2 \times 10^{4} \mathrm{ppm}$, the peak separation of N-Dia $\left[2 \times 10^{4} \mathrm{ppm}, 1.5 \mathrm{~kW}\right]$ became $108 \mathrm{mV}$ which is comparable to that of Dia $\left[10^{4} \mathrm{ppm}, 1.5 \mathrm{~kW}\right]$. These results indicate that small amount of nitrogen partly prevented boron atoms from entering the diamond lattice, and the concentration of doped boron in the diamond thin films can thus be recovered by increasing the boron concentration in the source solution even in the nitrogencontaining atmosphere, during MPCVD. 


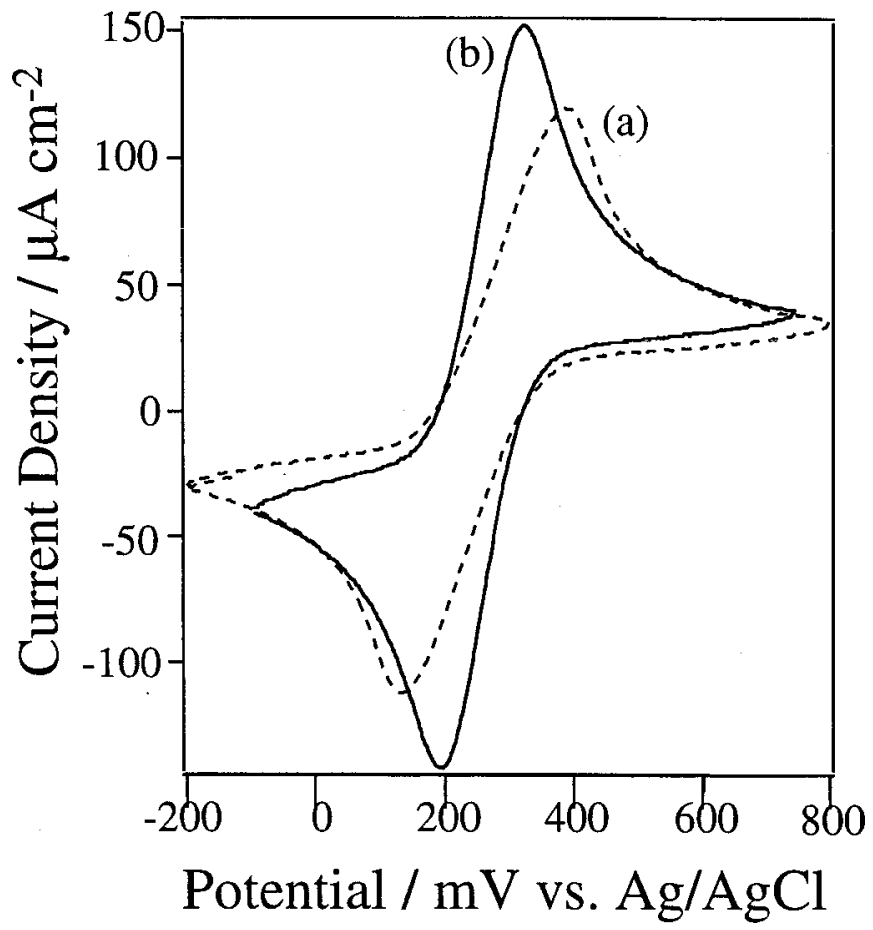

Figure 3. CVs of (a) N-Dia $\left[10^{4} \mathrm{ppm}, 1.5 \mathrm{~kW}\right]$ and (b) N-Dia $\left[2 \times 10^{4}\right.$ ppm, $1.5 \mathrm{~kW}$ ] electrodes, measured in $0.1 \mathrm{M} \mathrm{Na}_{2} \mathrm{SO}_{4}$ solution containing $\mathrm{K}_{3} \mathrm{Fe}(\mathrm{CN})_{6}$. Sweep rate was $100 \mathrm{mV} \mathrm{s}^{-1}$.

In Fig. 4, CVs in $0.1 \mathrm{M} \mathrm{H}_{2} \mathrm{SO}_{4}$ of (a) the Dia $\left[10^{4} \mathrm{ppm}, 5 \mathrm{~kW}\right]$ and (b) the N-Dia $\left[2 \times 10^{4} \mathrm{ppm}, 5 \mathrm{~kW}\right]$ electrodes are shown. It is clear that the addition of a small amount of nitrogen led to the broadening of the potential window. The estimated values of the potential window for every electrode investigated in the present study are summarized in Table I. At the diamond films grown under high plasma power $(5 \mathrm{~kW})$, introduction of nitrogen during MPCVD affected only the overpotential for hydrogen evolution, although the attenuation of plasma power caused an increase in the overpotentials for both the hydrogen and oxygen evolutions.

XPS measurement was employed to determine whether nitrogen atoms were incorporated in the diamond lattice. Depth profiles of $\mathrm{N}$ 1s core level XPS spectra of (a) N-Dia and (b) Dia by means of Ar sputtering are shown in Fig. 5. It is interesting to note that the $\mathrm{N} \mathrm{1s}$ peaks of almost the same intensity were observed in the bulk of both samples. This means that the small amount of nitrogen existed regardless of nitrogen bubbling, because the basic vacuum level of the chamber is not so high ( $10^{-3}$ Torr). However, the effect of intential addition of the nitrogen gas can be found in the $\mathrm{N} 1 \mathrm{~s}$ spectra of the surface region (compare the bottom two spectra in Fig. 5). While the $\mathrm{N}$ 1s peak was clearly observed for the N-Dia $\left[2 \times 10^{4} \mathrm{ppm}, 1.5\right.$ $\mathrm{kW}]$ film, that of the Dia $\left[10^{4} \mathrm{ppm}, 1.5 \mathrm{~kW}\right]$ film was hardly seen.

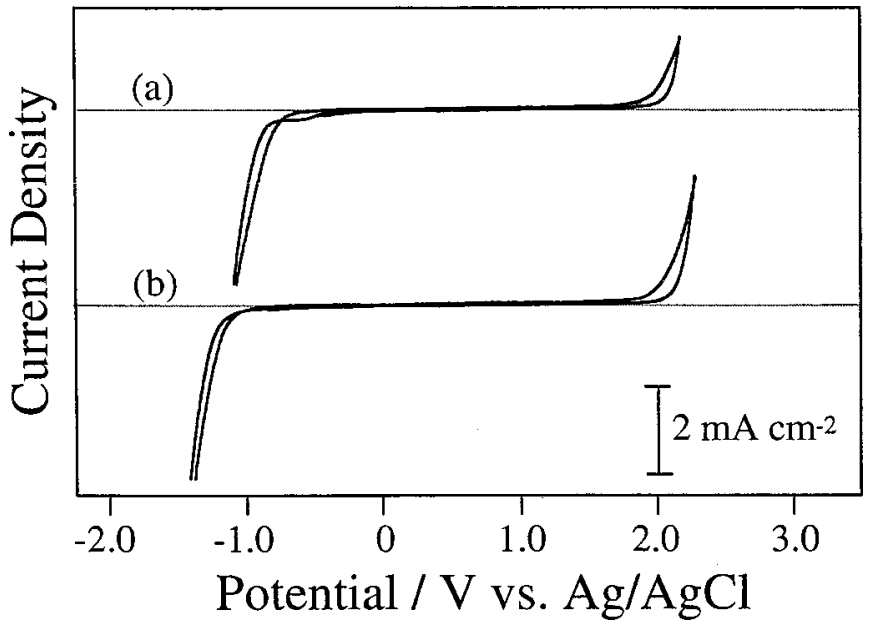

Figure 4. CVs of (a) the Dia $\left[10^{4} \mathrm{ppm}, 5 \mathrm{~kW}\right]$ and (b) the N-Dia [2 $\times 10^{4} \mathrm{ppm}, 5 \mathrm{~kW}$ ] electrodes in $0.1 \mathrm{M} \mathrm{H}_{2} \mathrm{SO}_{4}$ solution. Sweep rate was 100 $\mathrm{mV} \mathrm{s}^{-1}$.

The incorporated nitrogen atom in the surface region of Dia $\left[10^{4}\right.$ ppm, $1.5 \mathrm{~kW}$ ] may be sputtered out by the exposure to hydrogen plasma during the stepwise attenuation of plasma power at the end of the plasma MPCVD process. A slightly higher concentration of nitrogen gas in the MPCVD chamber can cause the partial preservation of nitrogen atoms in the surface region of N-Dia $\left[2 \times 10^{4}\right.$ ppm, $1.5 \mathrm{~kW}$. A comparable increase in the intensity of the $\mathrm{N} 1 \mathrm{~s}$ peak was also observed at BDD films chemically modified with dinitrophenylhydrazine (DNPH) molecules which contain four nitrogen atoms per molecule, and the surface coverage of DNPH was reported to be only $5 \%$ of the diamond surface. ${ }^{22}$ Although Notsu et al. did not report any shift of the $\mathrm{N} 1 \mathrm{~s}$ peak, a higher energy shift of the peak was observed in the present study in the spectrum of surface region of the N-Dia $\left[2 \times 10^{4} \mathrm{ppm}, 1.5 \mathrm{~kW}\right]$. This can be attributed to the generation of surface species containing nitrogen. We cannot, however, assign any chemical group, since the determination of the exact energy of the $\mathrm{N} 1 \mathrm{~s}$ peak was impossible because of the shift and shape change of the $\mathrm{C} 1$ s peak, which was used as the internal standard of the peak energy. Such a shift and a shape change of the $\mathrm{C} 1 \mathrm{~s}$ peak by the formation of surface species has been well known. ${ }^{23,24}$ In any case, we can conclude that the effect of the addition of nitrogen in the plasma chamber on the electrochemical properties was not induced by the nitrogen atoms in the crystal lattice, but by the existence of a submonolayer amount of surface species containing nitrogen.

Chemical termination of diamond surfaces has been known to affect the electrochemical properties. For example, conversion of hydrogen termination to oxygen termination of a BDD electrode caused a slight broadening of the potential window and reduction of the electron transfer rate for several redox systems. ${ }^{23}$ If a nitrogencontaining chemical species exists at $\mathrm{N}$-Dia surfaces, the reactivities

Table I. Comparison of the potential window of various diamond electrodes investigated in the present study in $0.1 \mathrm{M} \mathrm{H}_{2} \mathrm{SO}_{4}$ solution at the sweep rate of $100 \mathrm{mV} \mathrm{s}$.

\begin{tabular}{|c|c|c|c|}
\hline & $\begin{array}{l}\text { Negative limit }{ }^{\mathrm{a}} \\
\text { (V) }\end{array}$ & $\begin{array}{l}\text { Positive limit } \\
\text { (V) }\end{array}$ & $\begin{array}{l}\text { Potential window } \\
\text { (V) }\end{array}$ \\
\hline Dia $\left[10^{4} \mathrm{ppm}, 5 \mathrm{~kW}\right]$ & -0.950 & 2.125 & 3.075 \\
\hline $\mathrm{N}$-Dia $\left[2 \times 10^{4} \mathrm{ppm}, 5 \mathrm{~kW}\right]$ & -1.232 & 2.147 & 3.379 \\
\hline $\mathrm{N}-\mathrm{Dia}\left[2 \times 10^{4} \mathrm{ppm}, 1.5 \mathrm{~kW}\right]$ & -1.497 & 2.157 & 3.654 \\
\hline
\end{tabular}

a The negative potential limit was defined as the potential where the hydrogen evolution current reached $-1.0 \mathrm{~mA} \mathrm{~cm}$.

${ }^{\mathrm{b}}$ The positive potential limit was defined as the potential where the oxygen evolution current reached $+1.0 \mathrm{~mA} \mathrm{~cm}{ }^{-2}$. 


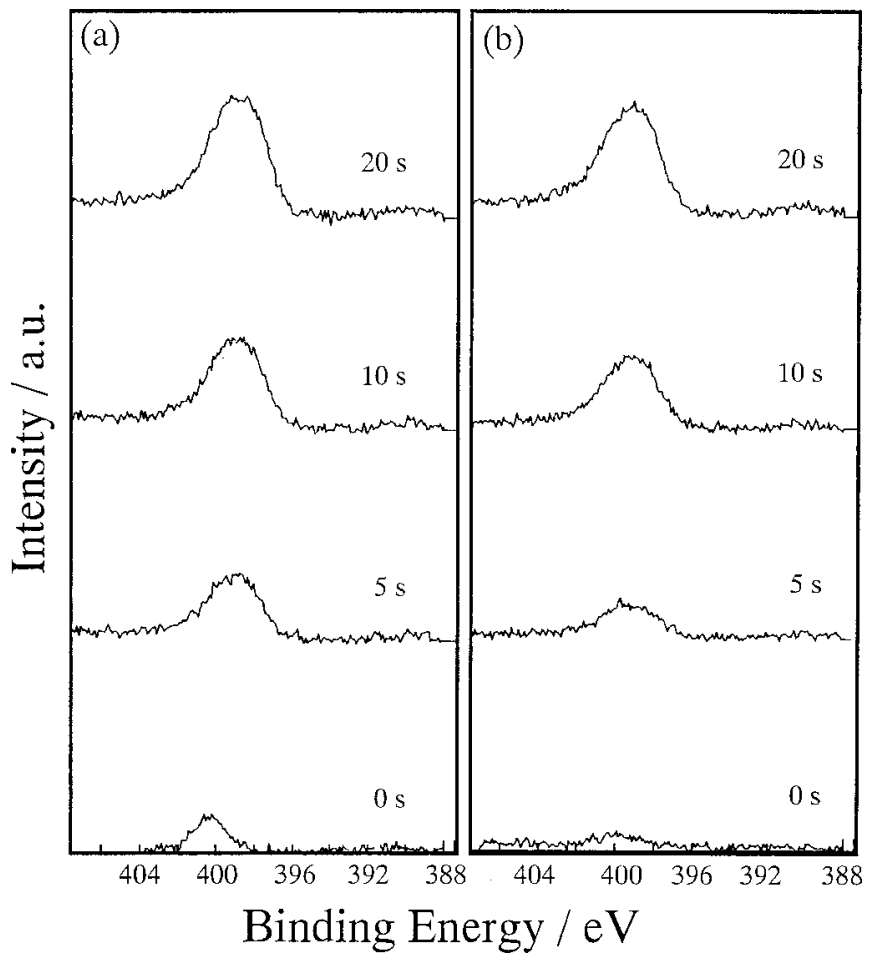

Figure 5. Depth profiles of $\mathrm{N}$ 1s core level XPS spectra of (a) N-Dia [2 $\left.\times 10^{4} \mathrm{ppm}, 1.5 \mathrm{~kW}\right]$ film and (b) Dia $\left[10^{4} \mathrm{ppm}, 5 \mathrm{~kW}\right]$ film. The times shown in the figure indicate the Ar sputtering time. In the case of Ar sputtering of $\mathrm{C}$, the etching rate is about $0.1 \mathrm{~nm} \mathrm{~s}^{-1}$ in the present XPS system.

for redox species, hydrogen, and oxygen evolutions may change. To confirm the existence of unique surface species at N-Dia, anodic oxidation $^{24}$ of an N-Dia $\left[2 \times 10^{4} \mathrm{ppm}, 1.5 \mathrm{~kW}\right]$ surface was carried out. In Fig. 6, CVs of (a) as-deposited N-Dia [ $2 \times 10^{4} \mathrm{ppm}, 1.5$ $\mathrm{kW}]$ and anodically oxidized N-Dia [ $\left.2 \times 10^{4} \mathrm{ppm}, 1.5 \mathrm{~kW}\right]$ at 2.5 $\mathrm{V}$ in $0.1 \mathrm{M} \mathrm{H}_{2} \mathrm{SO}_{4}$ are shown. A positive shift of the potential window after anodic oxidation is clear, although a slight broadening of the potential window in both positive and negative directions by the same treatment was observed at Dia. ${ }^{23}$ The present result suggests the possibility that the surface species at N-Dia is different from H-termination at Dia. The overpotentials for hydrogen and oxygen evolution should be affected by the surface termination, because these reactions are well known to involve adsorption of an intermediate. At the present, we can expect that the surface termination at $\mathrm{N}$-Dia is a nitrogen-containing species with a neutral or positive charge such as an amine group, because the electron transfer rate for the $\mathrm{Fe}(\mathrm{CN})_{6}^{3-/ 4-}$ redox system at N-Dia $\left[2 \times 10^{4} \mathrm{ppm}, 1.5 \mathrm{~kW}\right]$ is comparable to Dia $\left[10^{4} \mathrm{ppm}, 5 \mathrm{~kW}\right]$ as shown in Fig. 3b. If chemical groups with a negative charge or a large dipole exist at N-Dia $\left[2 \times 10^{4} \mathrm{ppm}, 1.5 \mathrm{~kW}\right.$ ], the electron transfer rate for the $\mathrm{Fe}(\mathrm{CN})_{6}^{3-14-}$ redox system should decrease as well as that at the oxygen terminated diamond electrode. ${ }^{23}$

The exposure of different facets of the diamond crystals can also be a possible factor in the broadening of the potential window at $\mathrm{N}$-Dia. The dominant growth of a (100) textured film by nitrogen introduction has been reported by several groups. ${ }^{12,14}$ In recent reports, the potential window of a diamond (100) single crystal ${ }^{25}$ is much larger than that of a (111) single crystal electrode. ${ }^{26}$ Thus, the increase in the (100) texturing at the N-Dia surface can contribute to the broadening of the potential window. X-ray diffraction (XRD) was used to estimate the dominant facet of the grown films. Although a small (400) peak at $2 \theta=119.52^{\circ}$ was observed in the XRD pattern of N-Dia $\left[2 \times 10^{4} \mathrm{ppm}, 5 \mathrm{~kW}\right.$ ], the peak height is almost the same as that of Dia $\left[10^{4} \mathrm{ppm}, 5 \mathrm{~kW}\right]$ grown for the same

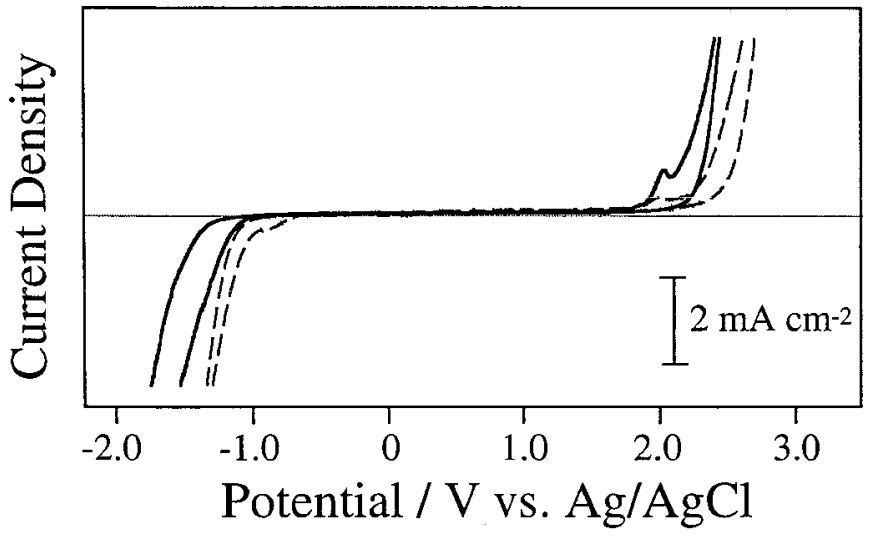

Figure 6. CVs of (a) as-deposited N-Dia $\left[2 \times 10^{4} \mathrm{ppm}, 1.5 \mathrm{~kW}\right]$ and anodically oxidized N-Dia $\left[2 \times 10^{4} \mathrm{ppm}, 1.5 \mathrm{~kW}\right]$ at $2.5 \mathrm{~V}$ in $0.1 \mathrm{M} \mathrm{H}_{2} \mathrm{SO}_{4}$ solution. Sweep rate was $100 \mathrm{mV} \mathrm{s}^{-1}$.

time $(8 \mathrm{~h})$, indicating that the increase in crystal growth in the (100) direction was not induced by the presence of nitrogen in the MPCVD chamber. Furthermore, the (100)-oriented square texture was not dominated in the scanning electron microscope images of $\mathrm{N}$-Dia. The dominant growth of the (100)-oriented diamond crystal should require a larger nitrogen pressure as has been reported, ${ }^{12,14}$ and this factor may be negligible for the expansion of the potential window at N-Dia.

\section{Conclusion}

The potential window of diamond electrode became larger by both the attenuation of plasma power and introduction of a small amount of nitrogen during MPCVD growth. The attenuation of plasma power caused slower and defect-free growth of diamond crystals and increased the overpotentials for both hydrogen and oxygen evolutions. For the effect of nitrogen, the existence of $\mathrm{N}$-containing surface termination seemed to cause the increase in overpotential for hydrogen evolution. A detailed characterization of the surface chemical group at N-Dia is underway.

\section{Acknowledgment}

This work was supported by the Japan Society for the Promotion of Science (JSPS) for the Future Program "Exploratory Research on Novel Artificial Materials and Substances for Next-Generation Industries" and by Grants-in-Aid for Priority Area Researchs on "New Protium Function" from the Ministry of Education, Science, Sports and Culture, Japan. Professor Katsuaki Shimazu (Hokkaido University) is acknowledged for making the X-ray photoelectron spectroscopy possible.

Hokkaido University assisted in meeting the publication costs of this article.

\section{References}

1. G. M. Swain, Adv. Mater., 6, 388 (1994).

2. G. M. Swain and R. Ramesham, Anal. Chem., 65, 345 (1993).

3. R. Tenne and Lévy-Clément, Isr. J. Chem., 38, 57 (1998).

4. G. M. Swain, A. B. Anderson, and J. C. Angus, MRS Bull., 23, 56 (1998).

5. G. Popovici and M. A. Prelas, Diamond Relat. Mater, 4, 1305 (1995).

6. K. Yoo, B. Miller, R. Kalish, and X. Shi, Electrochem. Solid-State Lett., 2, 233 (1999).

7. M. Kawaguchi, T. Kawashima, and T. Nakajima, Denki Kagaku oyobi Kogyo Butsuri Kagaku, 61, 1403 (1993).

8. M. Dinescu, A. Perrone, A. P. Caricato, L. Mirenghi, C. Gerardi, C. Ghica, and L. Frunza, Appl. Surf. Sci., 129, 692 (1998).

9. S. Itoh, Diamond Films Technol., 7, 195 (1997).

10. H. Konno, T. Nakahashi, M. Inagaki, and T. Sogabe, Carbon, 37, 471 (1999)

11. P. Hartmann, R. Haubner, and B. Lux, Diamond Relat. Mater., 6, 456 (1997).

12. J. Asmussen, J. Mossbrucker, S. Khatami, W. S. Huang, B. Wriht, and V. Ayres, Diamond Relat. Mater, 8, 220 (1999).

13. R. Locher, W. C. N. Herres, D. Behr, and P. Koidl, Appl. Phys. Lett., 65, 34 (1994). 
14. J. J. Schermer and F. K. de Theije, Diamond Relat. Mater, 8, 2127 (1999).

15. H. B. Martin, A. Argoitia, U. Landau, A. B. Anderson, and J. C. Angus, J. Electrochem. Soc., 143, L133 (1996).

16. J. D. Shovlin and M. E. Kordesch, Appl. Phys. Lett., 65, 863 (1994).

17. Z.-H. Huang, P. H. Cutler, N. M. Miskovsky, and T. E. Sullivan, J. Vac. Sci. Technol. B, 13, 526 (1995).

18. G. Gonon, A. Gheeraert, A. Deneuville, F. Fontaine, L. Abello, and G. Lucazeau, J. Appl. Phys., 78, 7059 (1995).

19. R. G. Buckley, D. Moustakas, L. Ye, and J. Varon, Appl. Phys. A: Solids Surf., 66, 3595 (1989)

20. T. Yano, D. A. Tryk, K. Hashimoto, and A. Fujishima, J. Electrochem. Soc., 145, 1870 (1998)
21. S. Sonoda, J. H. Won, H. Yagi, A. Hatta, T. Ito, and A. Hiraki, Appl. Phys. Lett., 70, 2574 (1997).

22. H. Notsu, I. Yagi, T. Tatsuma, D. A. Tryk, and A. Fujishima, J. Electroanal. Chem., 492, $31(2000)$

23. I. Yagi, H. Notsu, T. Kondo, D. A. Tryk, and A. Fujishima, J. Electroanal. Chem., 473, 173 (1999).

24. H. Notsu, I. Yagi, T. Tatsuma, D. A. Tryk, and A. Fujishima, Electrochem. SolidState Lett., 2, 522 (1999)

25. M. Yanagisawa, L. Jiang, D. A. Tryk, K. Hashimoto, and A. Fujishima, Diamond Relat. Mater., 8, 2059 (1999).

26. H. B. Martin, A. Argoitia, J. C. Angus, and U. Landau, J. Electrochem. Soc., 146, 2959 (1999). 